\title{
Chk1 suppressed cell death
}

\author{
Mark Meuth
}

\begin{abstract}
The role of Chk1 in the cellular response to DNA replication stress is well established. However recent work indicates a novel role for Chk1 in the suppression of apoptosis following the disruption of DNA replication or DNA damage. This review will consider these findings in the context of known pathways of Chk1 signalling and potential applications of therapies that target Chk1.
\end{abstract}

\section{Review}

The orderly and accurate replication of DNA is essential for the maintenance of genetic stability in cells. Cell cycle checkpoints play a critical role in this process by sensing DNA damage or aberrant replication structures and then slowing entry into S-phase, progression through S-phase, and mitosis to facilitate repair [1]. Recent work from a number of laboratories shows that some of these checkpoint responses regulate apoptosis in response to disruptions of DNA replication. Cell death helps maintain genetic stability by eliminating damaged cells that are not likely to be repaired. Thus a balance between cell cycle arrest and repair and the induction of cell death that is determined by checkpoints is critical for the preservation of genetic integrity. p53 plays a major role in the induction of apoptosis through the transcriptional activation of proapoptotic genes such as BAX and PUMA in response to DNA damage [2-4]. Thus in tumour cells deficient in p53 the balance between cell death and cell cycle arrest/repair is compromised. If repair is incomplete or inaccurate, genetic abnormalities may accumulate in p53-deficient tumour cells in part because cells acquiring DNA damage are no longer committed to death. Recently a number of laboratories using very different approaches have attempted to restore apoptotic responses in tumour cells to make them more responsive to therapeutic agents. Intriguingly several of these efforts have become focused on the checkpoint kinase, Chk1, as being particularly critical for the control of apoptosis in tumour cells. Here I will review recent work implicating

Correspondence: m.meuth@sheffield.ac.uk Institute for Cancer Studies, University of Sheffield, School of Medicine and Biomedical Sciences, Sheffield S10 2RX, UK
Chk1 as a key mediator of death in tumour cells in response to the disruption of DNA replication.

\section{The ATR-Chk1 pathway primarily responds to ssDNA generated by DNA replication stress}

Chk1 is critical to a wide range of responses to DNA replication stress and some forms of DNA damage. Chk1 is rapidly phosphorylated at several sites in an Ataxia telangiectasia mutated and Rad3 related (ATR)dependent manner after inhibition of DNA replication [5]. These post translational modifications are required to trigger cell cycle checkpoints in S and G2 [6], suppress inappropriate firing of late or cryptic DNA replication origins [7], and maintain replication fork integrity $[8,9]$. The roles of Chk1 in cell cycle checkpoints overlap with those of another DNA damage response pathway controlled by the Ataxia telangiectasia mutated (ATM) protein and its downstream phosphorylation target Chk2. For example, both Chk1 and Chk2 phosphorylate Cdc25A targeting it for degradation by ubiquitinmediated proteolysis $[6,10]$. In the absence of Cdc25A the $\mathrm{Cdk} 2 /$ cyclinE/A complex is inactive and S-phase arrest ensues. However the two pathways respond to different signals: single stranded DNA (ssDNA) for ATRChk1 and DNA double stranded breaks (DSBs), DNA double stranded ends, or collapsed replication forks for ATM-Chk2.

Although an expanding family of proteins appears to be necessary for Chk1 activation, much work implicates ssDNA generated by the inhibition of DNA replication as being critical for the ATR-mediated activation of Chk1. Replication progression is driven by the coordinated action of the replication helicase and DNA replication complexes. Work with Xenopus laevis egg extracts indicates that when replication is inhibited, the 
unwinding of DNA continues while the replication complex is stalled leading to the generation of ssDNA [11]. This ssDNA is rapidly coated by replication protein A (RPA) and the resulting RPA-ssDNA complex recruits ATR through the ATR interacting protein (ATRIP) [12]. The heterotrimeric Rad9-Rad1-Hus1 (9-1-1) DNA clamp is then loaded onto ssDNA regions by the Rad17RFC2-5 complex $[13,14]$ and TopBP1 is recruited to the stalled forks through its interactions with the 9-1-1 and ATR-ATRIP complexes $[15,16]$. Other proteins (including Claspin [17,18], Brit1/Mcph1 [19], and FANCM/ FAAP24 [20]) have been reported to be essential for the efficient activation of Chk1. Still further proteins (including FancJ [21] and Tim-Tipin [22]) appear to influence Chk1 activation through their roles in the generation of ssDNA. In vitro biochemical studies of potential substrates for the initial DNA binding reactions using static heteroduplex DNAs and Xenopus egg extracts show that 5'ssDNA-dsDNA junctions arising on either leading or lagging strands are most effective for Chk1 activation [23,24]. Thus these studies implicate primed ssDNA at stalled replication forks as being an effective substrate for the activation of this damage response pathway in this model system.

ssDNA generated during the repair of some types of DNA damage also triggers Chk1 activation. End processing at ionizing radiation (IR)-induced DNA DSBs by the Mre11-Rad50-NBS1 complex that is initiated by ATM can generate ssDNA and activate Chk1 [25].

\section{Cellular consequences of loss of Chk1}

Although deletion of Chk1 in mouse ES cells is lethal $[26,27]$, many other cell types survive partial or complete loss of Chk1 function. Chk1-/- chicken DT40 cells remain viable although their growth is slowed (in part due to an increase in the level of spontaneous apoptosis, [28]). Additionally, Chk1 inhibitors are not uniformly toxic to cells at concentrations where Chk1 function is compromised and siRNA-mediated depletions of Chk1 do not invariably cause cell death [29-31]. However cells with a defective Chk1 response show increased sensitivity to wide range of DNA damaging agents and replication inhibitors. This is particularly evident in the form of an enhanced level of apoptosis in cells where Chk1 function is compromised by genetic knockouts, siRNAmediated depletions or treatment with Chk1 inhibitors following exposure to agents that interfere with DNA replication [29-31] (Figure 1). This apoptotic response is caspase-3 dependent and appears to be initiated in cells in early S phase $[29,30]$. The onset of apoptosis is not rapid, Chk1 depleted cells become committed to death by 16 to $24 \mathrm{~h}$ after exposure to the replication inhibitors while Annexin V and caspase-3 induction occur somewhat later [32]. The response can be triggered in both p53 proficient and deficient cell lines. It was reported that primary human diploid fibroblasts treated with Chk1 inhibitors did not show this apoptotic response [29]. However there have been no further studies using primary cells and this should be confirmed with other cell types.

siRNA-mediated depletions of other DNA damage response proteins indicate that the apoptotic response is specific for cells defective in ATR-Chk1 signalling following disruption of DNA replication [33]. Tumour cell lines depleted of ATR showed a similar apoptotic response to replication inhibitors as the same cells depleted of Chk1 and co-depletion of ATR and Chk1 had no further effect. In contrast depletion of components of the ATM-mediated protein kinase cascade (ATM, Chk2, NBS1, or MRE11) had no significant effect on the apoptotic response to replication inhibitors. In addition, apoptotic responses of immortalized fibroblasts originating from individuals predisposed to cancer as a result of inherited mutations of ATM or NBS1 were not altered following treatment with replication inhibitors relative to cells corrected for these defects. Loss of the ATM-mediated signalling also does not alter the death response in ATR or Chk1-depleted cells.

These observations contrast with the central role played by the ATM-mediated protein kinase cascade in the apoptotic response to IR (Figure 1). ATM is central to the cellular response to DNA DSBs. In addition to its role in cell cycle checkpoints, this signalling cascade controls the onset of apoptosis following IR through the p53-mediated transcriptional activation of pro-apoptotic proteins such as BAX and PUMA [2-4]. Embryonic fibroblasts obtained form ATM-/-, Chk2-/-, NBS1-/- or p53-/- mice show defects in the induction of apoptosis by IR. MEFs deficient in ATM are partially defective while p53 deficient cells show a more complete resistance to the induction of apoptosis [34,35] although knockouts of both Chk2 and ATM show levels of apoptosis similar to those found in p53-/- cells [35]. Thus both ATM-dependent and independent pathways regulate the induction of apoptosis by IR.

While IR-induced apoptosis is suppressed in p53 deficient cells, recent work has shown that cell death can be restored by depletion of Chk1 [31] (Figure 1). A morpholino screen of p53 deficient zebrafish embryos revealed that radiation-induced apoptosis could be restored by knockdown of Chk1. Intriguingly this novel death pathway was caspase- 2 dependent and was not affected by overexpression of $\mathrm{bcl} 2 / \mathrm{xl}$. In further contrast to the caspase-3-dependent pathway triggered by replication inhibitors in the absence of Chk1, the response to IR is dependent upon both ATM and ATR. This death response is conserved in human p53 deficient tumour cells. Depletion or inhibition of Chk1 in such 


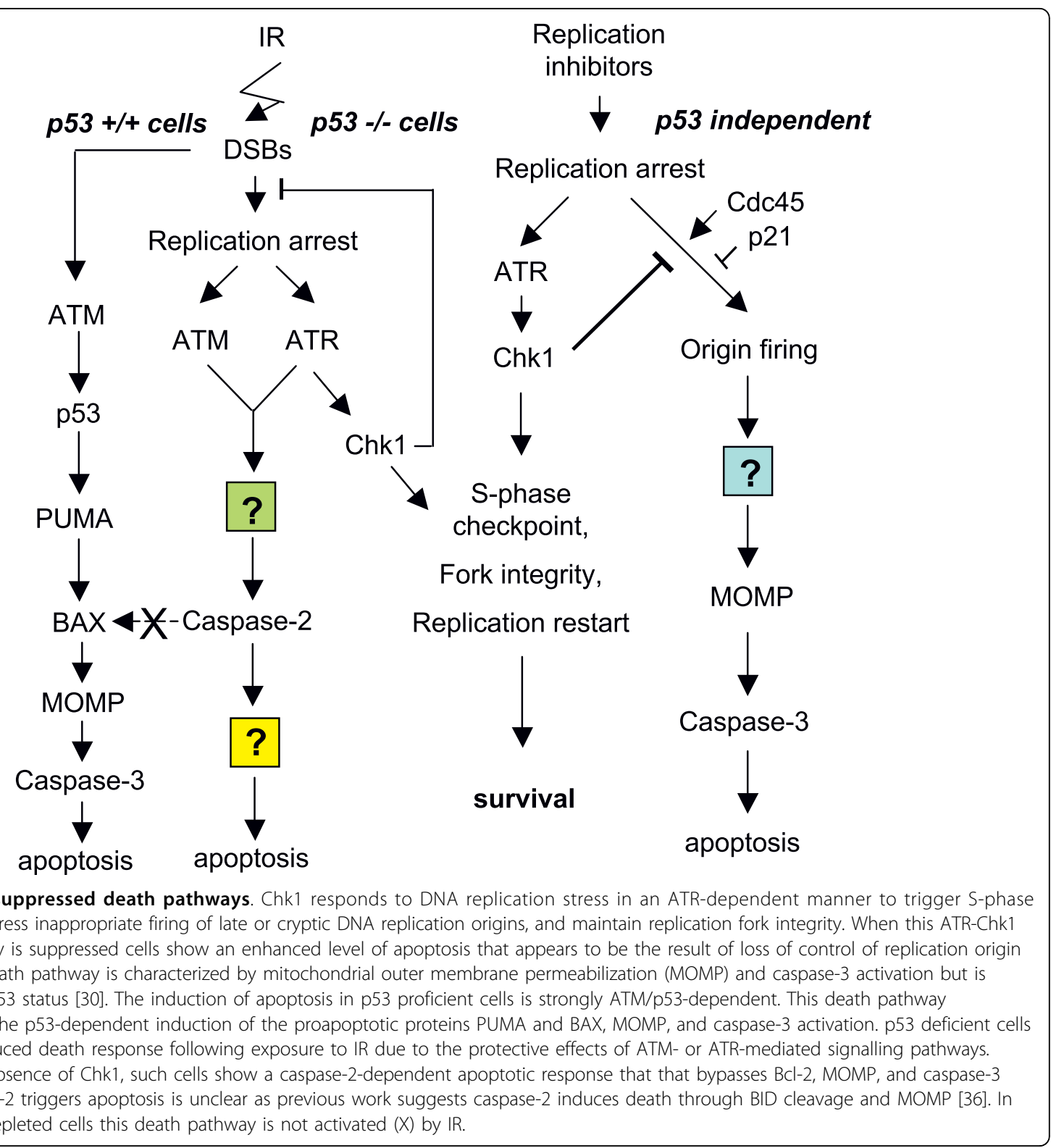

tumour cells induced a caspase- 2 dependent apoptotic response that was not detected in a p53 proficient line or in Chk1 depleted cells treated with replication inhibitors. How caspase-2 induces apoptosis is not clear as it is not an executioner caspase. Caspase-2 is thought to function upstream to cleave and activate BID that in turn causes mitochondrial outer membrane permeabilization, cytochrome c release, and activation of executioner caspases [36]. However this mitochondrial pathway does not appear to participate in the induction of death by IR in the absence of Chk1. Nevertheless, these findings reveal that Chk1 controls distinct cell death pathways triggered by DNA damage or perturbations of DNA metabolism.

\section{Mechanism(s)}

Precise molecular events initiating apoptosis in the absence of Chk1 are not clear. Chk1 has a number of roles in cells in response to DNA replication stress. We have initially attempted to investigate this mechanism by determining which of these roles is most critical for the control of apoptosis. These studies indicate that the role of Chk1 in the suppression of inappropriate firing of replication origins is the primary determinant [37]. The main evidence for this is the suppressive effect of Cdc45 depletion on apoptosis in Chk1-depleted cells. Cdc45 is an essential co-factor for the replication helicase and a component of a protein complex involved in DNA replication initiation in human cells $[38,39]$. 
Although both of these processes may be affected by Cdc45 depletion, the effect of Cdc45 depletion on apoptosis [37]is only seen where inappropriate origin firing occurs in cells depleted of Chk1 [7,37]. Consistent with this hypothesis apoptosis is enhanced in cells defective in the negative effector of origin firing, p21, following Chk1 depletion and treatment with a replication inhibitor [30].

We speculated that stalled forks may generate a signal for cell death that is amplified when further replication forks are arrested as a result of the inappropriate origin firing in the absence of Chk1. A number of events associated with the inappropriate origin firing have been reported that could potentially provide such signals. Early after the inhibition of DNA replication in Chk1 depleted or inhibited cells, enhanced levels of RPA and $\gamma \mathrm{H} 2 \mathrm{AX}$ foci relative to controls cells can be detected $[32,37]$. Since the formation of these foci is also dependent upon the function of Cdc45, it is likely that this accumulation is a result of inappropriately fired origins in the absence of Chk1. At later times the RPA32 subunit of RPA is hyperphosphorylated. This is followed by a strong induction of $\gamma \mathrm{H} 2 \mathrm{AX}$ and persistent activation of ATM and Chk2 [32]. Despite the very high level of $\gamma \mathrm{H} 2 \mathrm{AX}$ seen in some of the cells (evident as a pan nuclear staining of $\gamma \mathrm{H} 2 \mathrm{AX}$ ), these cells do not have detectable double strand breaks, consistent with previous reports for cells exposed to UV light [40]. Various reports have implicated $\mathrm{H} 2 \mathrm{AX}$ phosphorylation state and the recruitment of proapoptotic cJun-N-terminal kinase (JNK1) after DNA damage [41,42]. Yet the Chk1depleted cells showing the high levels of $\gamma \mathrm{H} 2 \mathrm{AX}$ are not committed to apoptosis. They can restart DNA synthesis if the replication inhibitor is removed but this does not resume at the sites of $\gamma \mathrm{H} 2 \mathrm{AX}$ foci and these cells do not appear to progress through S-phase [32]. Therefore, sites of $\gamma \mathrm{H} 2 \mathrm{AX}$ staining may represent abandoned replication forks that cannot be restarted.

RPA is phosphorylated by cells in S phase [43] but can be hyperphosphorylated at a number of sites in response to some types of DNA damaging agents (e.g. IR, UV, or MNNG, [44]) or DNA replication inhibitors [45]. Recent work indicates that hyperphosphorylated RPA co-localizes with the homologous recombination (HR) repair protein Rad51 at sites of ssDNA following treatment with a replication inhibitor and that the hyperphosphorylated form of RPA is required for HR and the maintenance of cell viability under these conditions [45]. Although it cannot yet be ruled out that the enhanced level of hyperphosphorylated RPA somehow assumes a different role in Chk1 depleted cells where $\mathrm{HR}$ is compromised [9], these data suggest that hyperphosphorylated RPA also contributes to cell survival rather than death. So, the identity of a putative cell death "signal transducer" remains elusive.

\section{Therapeutic applications}

An exciting implication of this work is that tumour cells retain a cryptic apoptotic pathway that can be triggered by therapeutic replication inhibitors or even radiotherapy when Chk1 function is inhibited. Nevertheless the use of Chk1 inhibitors in therapy has not met with universal enthusiasm because of the important role played by Chk 1 in the maintenance chromosomal stability and viability in dividing cells. A mouse strain in which Chk1 was specifically disrupted in adult mammary cells showed enhanced apoptosis and developmental defects [46]. Conditional Chk1 heterozygosity in these cells caused inappropriate cell cycle transitions and chromosomal abnormalities. Chk1 is highly expressed in many types of tumours [47] and this may protect them from replication stress induced by hypoxia or nutrient deprivation during tumour development [48] or the consequences of inappropriate transitions into S-phase triggered by genetic alterations acquired by tumour cells. The Chk1 knockdown experiments suggest enhanced lethality for tumour cells may be obtained where the protein is only transiently depleted, thus reducing potential lethality and genetic instability in normal tissue caused by complete loss of Chk1 or long term haploinsufficiency as in the conditonally heterozygous mice. Recent work has shown that Chk1 inhibitors can be used to increase the sensitivity of tumour cells to replication inhibitors in vitro and in vivo [49]. However initial studies using the nonspecific Chk1 inhibitor UCN-01 met complications in the form of a much increased half life in human serum due to an unfavourable association with human $\alpha$-acid glycoprotein [50]. These difficulties may be overcome through the use of new and more specific Chk1 inhibitors [51] and several of these are already in phase I and II trails. It will be interesting to see whether the higher specificity of these agents improves the response.

An additional therapeutic application of Chk1 inhibitors was revealed by an siRNA screen for gene silencings synthetically lethal with Chk1 inhibition [52]. This screen identified genes required for Fanconi anemia pathway function as being particularly important for cell survival when Chk1 function was inhibited. Strikingly the effect of Chk1 inhibition and cisplatin in FA deficient cell lines was synergistic, suggesting that Chk1 inhibitors may be useful for the treatment of tumours containing mutations of FA genes or in combination with novel FA pathway inhibitors. 


\section{Conclusions}

Clearly much remains to be done to understand the mechanism(s) underlying Chk1 suppressed cell death. While findings thus far provide strong support for the use of Chk1 inhibitors in therapy, elucidation of mechanism(s) underlying Chk1 suppressed death may reveal novel therapeutic targets that may help overcome the resistance that frequently accompanies such targeted therapies.

\section{Conflict of interests}

The author declares that he has no competing interests.

\section{Acknowledgements}

The author is grateful to Spencer Collis and Ruth Thompson for suggestions regarding the manuscript. The author's research is supported by programme funding from Yorkshire Cancer Research.

Received: 20 August 2010 Accepted: 2 September 2010 Published: 2 September 2010

\section{References}

1. Harper JW, Elledge SJ: The DNA damage response: ten years after. Mol Cell 2007, 28:739-745.

2. Nakano K, Vousden KH: PUMA, a novel proapoptotic gene, is induced by p53. Mol Cell 2001, 7:683-694.

3. Yu J, Zhang L, Hwang PM, Kinzler KW, Vogelstein B: PUMA induces the rapid apoptosis of colorectal cancer cells. Mol Cell 2001, 7:673-682.

4. Yu J, Zhang L, Hwang PM, Rago C, Kinzler KW, Vogelstein B: Identification and classification of p53-regulated genes. Proc Natl Acad Sci USA 1999, 96:14517-14522.

5. Zhao H, Piwnica-Worms H: ATR-mediated checkpoint pathways regulate phosphorylation and activation of human Chk1. Mol Cell Biol 2001, 21:4129-4139.

6. Zhao H, Watkins JL, Piwnica-Worms H: Disruption of the checkpoint kinase1/cell division cycle $25 \mathrm{~A}$ pathway abrogates ionizing radiationinducd S and G2 checkpoints. Proc Natl Acad Sci USA 2002, 99:14795-14800.

7. Maya-Mendoza A, Petermann E, Gillespie DA, Caldecott KW, Jackson DA: Chk1 regulates the density of active replication origins during the vertabrate S phase. EMBO J 2007, 26:2719-2731.

8. Zachos G, Rainey MD, Gillespie DA: Chk1-dependent S-M checkpoint delay in vertebrate cells is linked to maintenance of viable replication structures. Mol Cell Biol 2005, 25:563-574.

9. Sorensen CS, Hansen LT, Dziegielewski J, Syljuasen RG, Lundin C, Bartek J, Helleday T: The cell-cycle checkpoint kinase Chk1 is required for mammalian homologous recombination repair. Nat Cell Biol 2005, 7:195-201.

10. Falck J, Malland N, Syljuasen RG, Bartek J, Lukas J: The ATM-Chk2-Cdc25A checkpoint pathway guards against radioresistant DNA synthesis. Nature 2001, 410:842-847.

11. Byun TS, Pacek M, Yee MC, Walter JC, Cimprich KA: Functional uncoupling of MCM helicase and DNA polymerase activities activates the ATRdependent checkpoint. Genes Dev 2005, 19(9):1040-1052.

12. Zou L, Elledge SJ: Sensing DNA damage through ATRIP recognition of RPA-ssDNA complexes. Science 2003, 300:1542-1548.

13. Bermudez VP, Lindesey-Boltz LA, Cesare AJ, Mainwa J, Griffith JD, Hurwitz J, Sancar A: Loading of the human 9-1-1 checkpoint complex onto DNA by the checkpoint clamp holder hRad17-replication factor $\mathrm{C}$ complex in vitro. Proc Natl Acad Sci USA 2003, 100:1633-1638.

14. Zou L, Liu D, Elledge SJ: Replication protein A-mediated recruitment and activation of Rad17 cpmplexes. Proc Natl Acad Sci USA 2003, 100:13827-13832.

15. Delacroix S, Wagner JM, Kobayashi M, Yamamoto K, Karnitz LM: The Rad9Hus1-Rad1 (9-1-1) clamp activates checkpoint signaling via TopBP1. Genes Dev 2007, 21(12):1472-1477.
16. Lee J, Kumagi A, Dunphy WG: The Rad9-Hus1-Rad1 checkpoint clamp regulates interaction of TopBP1 with ATR. J Biol Chem 2007, 282:28036-28044.

17. Kumagi WG, Dunphy WG: Claspin, a novel protein required for the activation of Chk1 during a DNA replication checkpoint response in Xenopus egg extracts. Mol Cell 2000, 6:839-849.

18. Chini CCS, Chen J: Claspin, a regulator of Chk1 in DNA replication stress pathway. DNA Repair 2004, 3:1033-1037.

19. Rai R, Dai H, Multani AS, Li K, Chin K, Gray J, Lahad JP, Liang J, Mills GB, Meric-Bernstam F, et al: BRIT1 regulates early DNA damage response, chromosomal integrity, and cancer. Cancer Cell 2006, 10:145-157.

20. Collis SJ, Ciccia A, Deans AJ, Horejsi Z, Martin JS, Maslen SL, Skehel M, Elledge SJ, West SC, Boulton SJ: FANCM and FAAP24 function in ATRmediated Checkpoint signaling independently of the Fanconi anemia core complex. Mol CEIl 2008, 32:313-324.

21. Gong Z, Kim J-E, Leung CCY, Glover JNM, Chen J: Bach1/FancJ acts with TopBP1 and participates early in DNA replication checkpoint control. Mol Cell 2010, 37:438-446.

22. Smith KD, Fu MA, Brown EJ: Tim-Tipin dysfunction creates an undispensible reliance on the ATR-Chk1 pathway for continued DNA synthesis. J Cell Biol 2009, 187:15-23.

23. MacDougall CA, Byun TS, Van C, Yee MC, Cimprich KA: The structural determinants of checkpoint activation. Genes Dev 2007, 21(8):898-903.

24. Van C, Yan S, Michael WM, Waga S, Cimprich KA: Continued primer synthesis at stalled replication forks contributes to checkpoint activation. J Cell Biol 2010, 189:233-246.

25. Jazayeri A, Falck J, Lukas C, Bartek J, Smith GC, Lukas J, Jackson SP: ATMand cell cycle-dependent regulation of ATR in response to DNA doublestrand breaks. Nat Cell Biol 2006, 8:37-45.

26. Liu Q, Guntuku S, Cui XS, Matsuoka S, Cortez D, Tamai K, Luo G, CarattiniRivera S, DeMayo F, Bradley A, et al: Chk1 is an essential kinase that is regulated by Atr and required for the G(2)/M DNA damage checkpoint. Genes Dev 2000, 14(12):1448-1459.

27. Takai H, Tominaga K, Motoyama N, Minamishima YA, Nagahama H, Tsukiyama T, Ikeda K, Nakayama K, Nakanishi M, Nakayama K: Aberrant cell cycle checkpoint function and early embryonic death in Chk1-/- mice. Genes Dev 2000, 14(12):1439-1447.

28. Zachos G, Rainey MD, Gillespie DA: Chk1-deficient tumour cells are viable but exhibit multiple checkpoint and survival defects. EMBO J 2003, 22:713-723.

29. Cho SH, Toouli CD, Fujii GH, Crain C, Parry D: Chk1 is essential for tumor cell viability following activation of the replication checkpoint. Cell Cycle 2005, 4:131-139.

30. Rodriguez R, Meuth M: Chk1 and p21 cooperate to prevent apoptosis during DNA replication fork stress. Mol Biol Cell 2006, 17:402-412.

31. Sidi S, Sanda T, Kennedy RD, Hagen AT, Jette CA, Hoffmans R, Pascual J, Imamura S, Kishi S, Amatruda JF, et al: Chk1 suppresses a caspase-2 apoptotic response to DNA damage that bypasses $\mathrm{p} 53, \mathrm{BCl}-2$, and caspase-3. Cell 2008, 133:2110-2118.

32. Gagou ME, Zuazua-Villar P, Meuth M: Enhanced H2AX phosphorylation, DNA replication fork arrest, and cell death in the absence of Chk1. Mol Biol Cell 2010, 21:739-752.

33. Myers K, Gagou ME, Zuazua-Villar P, Rodriguez R, Meuth M: ATR and Chk1 suppress a caspase-3-dependent apoptotic response following DNA replication stress. PLoS Genet 2009, 5:e1000324.

34. Stracker TH, Morales M, Couto SS, Hussein H, Petrini JH: The carboxy terminus of NBS1 is required for induction of apoptosis by the MRE11 complex. Nature 2007, 447:218-221.

35. Westphal $\mathrm{CH}$, Rowan $\mathrm{S}$, Schmaltz C, Elson A, Fisher DE, Leder P: Atm and p53 cooperate in apoptosis and suppression of tumorigenesis, but not in resistance to acute radiation toxicity. Nat Genet 1997, 16:397-401.

36. Kumar S: Caspase-2 in apoptosis, the DNA damage response and tumour suppression: enigma no more. Nat Rev Cancer 2009, 9:897-903.

37. Rodriguez R, Gagou ME, Meuth M: Apoptosis induced by replication inhibitors in Chk1-depleted cells is dependent upon the helicase cofactor Cdc45. Cell Death Differ 2008, 15:889-898.

38. Aparicio T, Guillou E, Coloma J, Montoya G, Mendez J: The human GINS complex associates with Cdc45 and MCM and is essential for DNA replication. Nucl Acids Res 2009, 37:2087-2095. 
39. Bauerschmidt C, Pollok S, Kremmer E, Nasheuer H-P, Grosse F: Interactions of human Cdc45 with the Mcm2-7 complex, the GINS complex, and DNA polymerases $d$ and e during $S$ phase. Genes Cells 2007, 12:745-758.

40. Marti TM, Hefner E, Feeney L, Natale V, Cleaver JE: H2AX phosphorylation within the G1 phase after UV irradiation depends upon nucleotide excision repair and not double-strand breaks. Proc Natl Acad Sci USA 2006, 103:9891-9896.

41. Lu C, Zhu F, Cho Y-Y, Tang F, Zykove T, Ma W-y, Bode AM, Dong Z: Cell apoptosis: requirement of $\mathrm{H} 2 \mathrm{AX}$ in DNA ladder formation, but not for the activation of caspase-3. Mol Cell 2006, 23:121-132.

42. Cook PJ, Ju BG, Telese F, Wang X, Glass CK, Rosenfeld MG: Tyrosine dephosphorylation of $\mathrm{H} 2 \mathrm{AX}$ modulates apoptosis and survival decisions. Nature 2009, 458:591-596.

43. Din S, Brill SJ, Fairman MP, Stillman B: Cell-cycle regulated phosphorylation of DNA replication factor A from human and yeast cells. Genes Dev 1990, 4(6):968-977.

44. Zou Y, Liu Y, Wu X, Shell SM: Functions of human replication protein $A$ (RPA): from DNA replication to DNA damage and stress responses. I Cell Physiol 2006, 208:267-273.

45. Shi W, Feng Z, Zhang J, Gonzalez-Suarez I, Vanderwaal RP, Wu X, Powell SN, Roti Roti JL, Gonzalo S, Zhang J: The role of RPA2 phosphorylation in homologous recombination in response to replication arrest. Carcinogenesis 2010, 31:994-1002.

46. Lam MH, Liu Q, Elledge SJ, Rosen JM: Chk1 is haploinsufficient for multiple functions critical to tumor suppression. Cancer Cell 2004, 6:45-59.

47. Verlinden L, Vanden Bempt I, Eelen G, Drijkoningen M, Verlinden I, Marchal K, De Wolf-Peeters C, Christiaens MR, Michiels L, Bouillon R, et al: The E2F-regulated gene Chk1 is highly expressed in triple-negative estrogen receptor/progesterone receptor/HER-2 breast carcinomas. Cancer Research 2007, 67:6574-6581.

48. Hammond EM, Dorie MJ, Giaccia AJ: Inhibition of ATR leads to increased sensitivity to hypoxia/reoxygenation. Cancer Research 2004, 64:6556-6562

49. Tse AN, Rendahl KG, Sheikh T, Cheema H, Aardalen K, Embry M, Ma S, Moler EJ, Ni ZJ, Lopes de Menezes DE, et al: CHIR-124, a novel potent inhibitor of Chk1, potentiates the cytotoxicity of topoisomerase I poisons in vitro and in vivo. Clin Cancer Res 2007, 13:591-602.

50. Fuse E, Tanii H, Kurata N, Kobayashi H, Shimada Y, Tamura T, Sasaki Y, Y T, Lush RD, Headlee D, et al: Unpredicted clinical pharmacology of UCN-01 caused by specific binding to human alpha1-acid glycoprotein. Cancer Research 1998, 58:3248-3253.

51. Janetka JW, Ashwell S: Checkpoint kinase inhibitors: a review of the patent literature. Expert Opin Ther Pat 2009, 19:165-197.

52. Chen CC, Kennedy RD, Sidi S, Look AT, D'Andrea AA: Chk1 inhibition as a strategy for targeting fanconi anemia (FA) DNA repair deficient tumors. Mol Cancer 2009, 8:24.

doi:10.1186/1747-1028-5-21

Cite this article as: Meuth: Chk1 suppressed cell death. Cell Division 2010 5:21.

\section{Submit your next manuscript to BioMed Central and take full advantage of:}

- Convenient online submission

- Thorough peer review

- No space constraints or color figure charges

- Immediate publication on acceptance

- Inclusion in PubMed, CAS, Scopus and Google Scholar

- Research which is freely available for redistribution

Submit your manuscript at www.biomedcentral.com/submit
Biomed Central 